\title{
EVALUATION OF SOUTH AFRICA'S PUBLIC AGRICULTURAL EXTENSION IN THE CONTEXT OF SUSTAINABLE AGRICULTURE
}

\author{
Khwidzhili, R. H. ${ }^{1}$ and Worth, S. ${ }^{2}$ \\ Correspondence Author: R. H. Khwidzhili, Email: humphrey.khwidzhili@ump.ac.za
}

\begin{abstract}
South Africa's public agricultural extension services evolved from as early as the beginning of 1900. Agricultural extension is now recognised as a science by the South African Council of Natural Science Profession (SACNASP). This paper presents a philosophical argument that the promotion of sustainable agricultural practices should remain the domain of public extension and advisory services. To provide context, the paper firstly defines agricultural extension and the role extension could play in promoting the five pillars of sustainable agriculture. Secondly, it evaluates the national policy on extension and advisory services to determine the extent to which it addresses the framework of the five pillars for sustainable agriculture. Thirdly, the paper evaluates the Extension Recovery Plan (ERP), norms and standards for agricultural extension and the National Development Plan (NDP) against the framework of sustainable agriculture. The evaluation indicates that only three pillars of sustainability are emphasised. There is a need to subdivide the traditional pillars to align with the full framework for sustainability. The initial findings suggest that, while South Africa's agricultural extension policy often refers to sustainability and even to sustainable agriculture, they do so using the traditional three-pillared framework of economic, environmental and social sustainability, and thus fall short on key elements essential to sustainable agriculture, namely maintaining and increasing biological productivity, decreasing the level of risk to ensure larger security, protecting the quality of natural resources, ensuring agricultural production is economically viable, and ensuring agricultural production is socially acceptable. The paper also explores government initiatives to support extension and advisory services. Finally, this paper concludes by emphasising that the national policy on extension and advisory services should be amended to suit the five pillars of sustainable agriculture.
\end{abstract}

Keywords: Sustainable agriculture, extension and advisory services, extension, pillars of sustainability, agricultural policy

\section{INTRODUCTION}

The continued provision of food, fuel and fibre to a growing world population depends, in large measures, on the practice of sustainable agriculture. This paper argues that, in the case of South Africa, adoption of sustainable agricultural practices falls in the domain primarily of public sector agricultural extension (Department of Agriculture (DOA), 2014). It is thus valuable to

\footnotetext{
${ }^{1}$ R. H. Khwidzhili. PhD student at the University of KwaZulu-Natal and Lecturer: Agricultural Extension and Rural Resource Management, University of Mpumalanga, P/Bag x 11283, Nelspruit, 1200. Tel. 013 002 0144 ; E mail: humphrey.khwidzhili@ump.ac.za. This article is part of the author's PhD Thesis at the University of KwaZulu-Natal, Pietermaritzburg Campus.

${ }^{2}$ Prof. S. Worth. Associate Professor: Agricultural Extension and Rural Resource Management \& Director: African Centre for Food Security, School of Agricultural, Earth and Environmental Sciences. University of KwaZulu Natal, P/Bag X01, Scottsville, 3209. Tel. 033 2605792; E mail worths@ukzn.ac.za
} 
understand the extent to which South Africa's public extension service is positioned to promote sustainable agriculture amongst the farmers it serves. This paper first examines the discipline of agricultural extension in the context of sustainability and discusses the role it should play in promoting sustainable agriculture. The paper then presents a brief outline of the evolution of public sector extension in South Africa, and argues that, given the role extension has played over the last several decades, the state extension service should be well-positioned to promote sustainable agriculture even if this has not been its primary focus in the past. Furthermore, since extension services are driven by policy, the paper examines the extent to which current South African national policy guiding extension and advisory services supports the promotion of sustainable agriculture using the five pillars of sustainable agriculture established by Khwidzhili and Worth (2016). Other initiatives to support extension and advisory services are also discussed.

\section{OBJECTIVES OF THE PAPER}

The main objective of this study is to evaluate public agricultural extension in South Africa and its alignments to the five pillars of sustainable agriculture. This entails the following:

- Defining agricultural extension and the role it plays in the agricultural sector;

- Providing an overview of the evolution of agricultural extension in South Africa;

- Evaluating the current national policy on extension and advisory services and other public documents in the context of South Africa's extension services' position to promote sustainable agriculture with specific reference to the five-pillars framework; and

- Providing guidance to policy makers for incorporating all five pillars of sustainable agriculture when developing agricultural extension policies and programmes.

\section{RESEARCH METHOD}

This was a desk-top study examining relevant policies documenting the involvement of South Africa's public extension services in the context of sustainable agriculture. The data analysed were drawn primarily from existing articles, documents and policies filtered through the five pillars of sustainable agriculture to identify embedded themes and recurring patterns of meaning and relationships (Cohen, Manion \& Morrison, 2002). This is a review paper based on already existing literature (Yin, 2003), in other words, secondary data. The following documents were evaluated as they were found to be relevant to the delivery of agricultural extension in South Africa: National Policy on Extension and Advisory Services; Extension Recovery Plan; and the Norms and Standards for Agricultural Extension and the National Development Plan.

\section{THE EVOLUTION OF PUBLIC AGRICULTURAL EXTENSION IN SOUTH AFRICA}

The evolution of agricultural extension in South Africa dates back to the reconstruction that followed from 1902 when agricultural scientists were imported from England. Drawing from expertise of outsiders was futile as they were unfamiliar to South Africa's local conditions. In response, in 1907, the first cohort of potential South African scientists was identified to study abroad (Van Vuuren, 1952). 
Agricultural extension began to take shape in South Africa around 1925, supported by the then National Ministry of Agriculture. The Ministry had approved approximately six agricultural advisors (extension officers) to serve the entire country in rendering extension services. The primary role of extension from its initial stage was to assist farmers to make decisions that will better their farming practices and ensure food security in the country (Koch \& Terblanche, 2013). In the early 1940s, agricultural extension was incorporated as an academic career within institutions of higher learning. This was initiated by the University of Pretoria, University of Stellenbosch and Elsenberg College of Agriculture where the faculties of agriculture were established (Van Vuuren, 1952). Over the ensuring decades, other South African universities and colleges began to offer agricultural extension programmes. Among these are the Universities of Fort Hare, KwaZulu-Natal, Limpopo, North West, Venda, Cape Peninsula University of Technology, and Tshwane University of Technology (Koch \& Terblanche, 2013). The now 11 agricultural colleges have also played an important role in training in agricultural advisors, particularly for the former so-called homelands. Concurrent with the expansion of extension in higher education, the profession of extension grew, and in 1966, the South African Society of Agricultural Extension (SASAE) was established at the University of Pretoria as a professional body supporting the extension practitioners.

Despite its inclusion in higher education programmes, and despite its contribution to the livelihood of farmers and the agricultural economy, for eight decades after the establishment of extension, agricultural extension was not considered as a science by the South African Council of Natural Science (SACNASP). However, the SASAE championed the cause of extension with SACNASP, and since 2013, agricultural extension has been officially recognised as a science (extension science) with three possible categories of registration (depending on the nature of the extension practitioner's qualification). The categories include professional (post-graduate degree in agricultural extension coupled with relevant experience), candidate (supported by a degree in agriculture with no experience in extension), and certificated scientist (supported by a degree in agriculture and at least some experience in agriculture).

The adoption of the South African Constitution in 1994 established that board extension policy (as an element of national aspects of agriculture) would be a national competency, while the delivery and management of extension to farmers would be done through the provincial governments, with substantial latitude regarding modes of operation, operational focus and developmental priorities. This resulted in nine separate extension services, which, while being bound to broad national policy, are not subject to any meaningful national coordination or collective accountability, rather they are solely accountable to the provincial legislatures and governments and ultimately individual provincial political leaders (Worth, 2012).

\section{PUBLIC AgRICULTURAL EXTENSION PERSPECTIVE AND THE ROLE IT PLAYS IN AGRICULTURE}

There is no single definition that can be used exclusively to define agricultural extension. According to the then South African Department of Agriculture (DOA, 2005), agricultural extension is the art of assisting commercial, small-scale and subsistence farmers with agricultural related knowledge and skills that will make them productive and competitive to ensure sustainability (Hedden-Dunkhorst \& Mollel, 1999). Van den Ban and Hawkins (1996) earlier defined extension as the conscious use of communication of information with the aim of assisting people to make good decisions. Purcell and Anderson (1997) similarly confirm that 
agricultural extension is a key element in enabling farmers to obtain information and technologies that can improve their livelihoods. The concept of a livelihood is broader and more comprehensive and integrated than simply 'farming'. A livelihood is a means of supporting one's existence most often through multiple strategies of which, for farmers, farming is one.

Most commonly, extension is generally viewed as a process of working with farmers or farming communities to help them acquire relevant and useful agricultural or related knowledge and skills in order to increase farm productivity, competitiveness, and sustainability (Düvel, 2004). However, in practice, it is a continuum ranging from the narrow technology transfer focusing specifically on farming practices within the specific context of an agricultural enterprise, to advisory services that address farming and related practices in the wider context of social, economic and environmental perspectives including education, human development and critical public priority issues such as food security, poverty alleviation, environmental degradation, and social equity (De Klerk et al., 2004).

Increasingly, the role of agricultural extension extends beyond technology transfer with a primary aim of assisting farmers to adopt new technology. Extension's role encompasses linking farmers to domestic and international markets, assisting farmers in reducing their vulnerability and enhancing their livelihoods, promoting environmental conservation (Alex, Zijp \& Byerelee, 2001), and taking a leading role in rural development and even non-farm employment (Rivera, Qamar \& Crowder, 2001). Extension is expected to include strengthening innovation processes and building linkages between farmers and other agencies, as well as assisting farmers with bargaining for inputs and access to credit to advance their farming practices (Aneato et al., 2012). In this expansive context, it is evident that agricultural extension requires a holistic approach.

Agricultural extension is an important factor in promoting agricultural development (Anderson \& Feder, 2007; Birkhaeuser, Evenson \& Feder, 1991). Most governments in sub-Saharan Africa, including South Africa, have invested in agricultural extension as the primary tool for improving agricultural productivity and farmers' income. In South Africa, agricultural extension is used to support agricultural development and specifically to play a pivotal role in educating farmers to practice more efficient and profitable farming. It is thus posited that South Africa's public agricultural extension should be well-suited to promote sustainable agriculture.

Agricultural extension services depend upon knowledge, skills, and insights concerning the multifaceted process of behaviour change (Griffith, 1994). While extension should help teach new farming practices and assist rural people to build leadership and organisational skills (Van der Ban \& Hawkins, 1996), more recently, extension has experienced a major shift towards participatory models (Düvel, 2005) in which stakeholders take a more active role in agricultural extension processes and decision-making. Most recently, there has been an introduction of a learning-based model that emphasises the need to build capacity for learning throughout the extension system, but especially among the farmers for which learning is described as the capacity to engage with scientific enquiry (Worth, 2006).

Table 1 summarises some common agricultural extension models that are used in South Africa. 


\section{Table 1: Extension models}

\begin{tabular}{|l|l|l|}
\hline Models & Core principles & Implications \\
\hline Linear & - Top-down approach & - Farmers cannot solve their \\
& - Based on extension expertise & problems \\
& - The farmer is the recipient & - Adoption of technology is not \\
questionable by farmers
\end{tabular}

Adapted from Abdu-Raheem and Worth (2011)

Depending on the aim and objective of an extension engagement or intervention, different extension models are used by extension. The first extension model in

Table 1 is called the linear model which focuses on transfer of technology in which the (mostly off-farm) extension research centre is the source of technology and innovation that is then 'transferred' to farmers who 'adopt' the technology (Röling, 1995). This is a so-called 'topdown approach' because the farmer is only the recipient of technology that has been designed and delivered 'from above.' The linear model requires high-level knowledge from specialised scientists and specialised extension skills to disseminate innovations to farmers (Dexter, 1986). However, not all farmers will adopt all new technology from extension practitioners, especially technology developed in their absence. Adoption of technology is influenced by the farmers' resources and their past experience. Thus, this approach is not appropriate in all cases, and should not be the 'default' approach.

The second extension model is the advisory model which views farmers as active problem solvers and will seek advice from extension only if they fail to solve their problems themselves (Röling, 1995). The model encourages farmers to share information and learn from each other with little influence from extension services. The advice from extension comes as a request from the farmer. The model recognises and appreciates the role that farmers could play in problem solving.

The third model is the participatory model where the knowledge and expertise of farmers (often referred to as indigenous knowledge) have accumulated over generations (Agrawal, 1995). This knowledge is best understood as local memory (the collection of practices handed down 
from past generations, but which is no longer used), local practice (knowledge compiled from various second-hand sources or unstructured trial and error), and/or local science (knowledge and practices currently in use or not a result of deliberate and conscious innovation and experimentation conducted by the farmer) (Masere \& Worth, 2016). Local science would result from an extension engagement that employs a learning posture with the primary aim of building capacity of farmers to learn, innovate and experiment systematically, methodically and deliberately (Worth, 2006). Thus, extension should recognise farmers' knowledge and should incorporate it in their work (Agrawal, 1995; Hart, 2003; Swanson, 2006).

The fourth model is a learning-centred model which focuses on learning amongst agricultural extension workers, researchers, farmers and other stakeholders. The model is based on continuous reflection amongst all stakeholders within the learning process (Worth, 2006). This model was evolved from the facilitation model and Chambers' (1997) participatory rural appraisal (PRA). It is grounded in Kolb's (1984) learning theory which embraces the iterative process of analysing, planning, acting, monitoring and evaluating (i.e. observing, reflecting, conceptualising and actively experimenting).

As noted earlier, no one extension model is suitable in all contexts. However, it can be argued that the participation of both the extension practitioner and farmers in addressing farmers' issues can yield profound benefits. It is thus imperative, whatever model is applied, that learning should be encouraged and promoted, as it is the basic component of knowledge management. Each stakeholder should be treated with respect and be afforded the opportunity to display and apply their expertise.

These shifts in approach and process suggest that extension services respond well to working within the bounds of theoretical frameworks, including those guiding sustainable agricultural practices (Rivera, 2006). Existing frameworks could be adopted, adjusted or developed and adapted to extension's multiple roles ranging from advisory, technician, educator, middleman, facilitator, analyst, researcher and learning partner (Bembridge, 1991; DOA, 2005, Düvel, 2005; Van den Ban \& Hawkins, 1996; Worth 2006). Globally, public agricultural extension is faced with a large challenge of being relevant and effective. To achieve this, it is essential to develop and implement relevant frameworks.

A case in point is a framework for sustainable agriculture. Currently, with regards to sustainable agriculture, agricultural extension advises farmers based on the three traditional pillars of sustainability, namely economic, environmental and social viability (Magoro \& Hlungwani, 2014). However, more current thinking suggests that a five-pillar framework should be applied (Khwidzhili \& Worth, 2016) which encompasses maintaining and increasing biological productivity, decreasing the level of risk to ensure larger security, protecting the quality of natural resources, ensuring agricultural production is economically viable, and ensuring agricultural production is socially acceptable.

The national policy on agricultural extension and advisory services has clearly defined the role of agricultural extension agents. The study also supports the four extension models described by Abdu-Reheem and Worth (2011), which extension can use to promote sustainable agriculture. As previously noted, no single approach suits all environments. Extension will have to choose approaches that will be relevant to their target clients (farmers), their situations, and the issues to be addressed.

However, the failure of the exclusive use of conventional top-down approaches which excluded farmers participation is well documented. Thus, in general, agricultural extension should 
prioritise participatory approaches when engaging farmers. Leeuwis and Van den Ban (1996), for example, argued that farmers should be involved directly in the planning of agricultural extension activities. Participatory agricultural extension encourages joint learning amongst farmers (Hagmann et al, 1999; Wettasinha, Veldhuizen \& Waters-Bayer, 2003). Promoting participation of farmers in the extension process reduces barriers that impact the rate of adopting sustainable agricultural practices (Ajeigbe \& Dashiell, 2010). Specifically, according to Nagel (1997), understanding, working with, accommodating and otherwise building on the local knowledge of farmers helps promote sustainable agricultural practices.

Early in the provision of extension to smallholder black South African farmers, Bembridge (1979) argued that extension services were meant to transfer skills and knowledge to farmers. This suggests that the knowledge and skills held within the agricultural extension system should be assessed and updated on a regular basis to ensure extension services stay relevant to the ever-changing agricultural landscape.

In addition to the knowledge and skills within extension and the choice of extension models and frameworks, the reach of the service is also an important factor. Williams et al. (2008) reported that access to quality extension and advisory services depends on the ratio of extension to farmers. The lack of distribution of extension and advisory services in South Africa was also highlighted as a major constraint for farmers (Ndoro, Mudhara \& Chimonyo, 2014; Nel \& Davies, 1999; Van Niekerk et al., 2011). They argued that the distribution of extension and advisory services is relatively low among emerging farmers (who arguably have the greatest need for extension), compared to so-called commercial farmers. The poor distribution contributes to the fact that most emerging farmers depend entirely on public extension services (Ngomane, Thomson \& Radhakrishna, 2002; Oladele \& Mabe, 2010), while commercial farmers rely on private extension that is often costly. Similarly, the South African Extension Recovery Implementation Plan (2008) indicated a lack of adequate extension services in the country, indicating the ratio of extension officers to farmers as 1:1500. This figure is still high considering that some farms are commercial (the scope of work is extended) while others are producing on a small scale. In addition, factors such as low morale, lack of mobility, and low salaries were found to contribute to high turnover in the extension services, and make it difficult to attract recruits (Belay \& Abebaw, 2004; Kaimowitz, 1991). The recovery plan was designed to address these various challenges in South African extension

\section{REVIEW OF SECONDARY SOURCES}

The study examined four public documents that are considered fundamental in promoting agricultural extension and advisory services in South Africa, namely the National Policy on Extension and Advisory Services, Norms and Standards for Agricultural Extension, Extension Recovery Plan, and the National Development Plan. A brief overview of these policies is presented below.

\subsection{National Policy on Extension and Advisory Services (NPEAS)}

South Africa developed a national policy on extension and advisory services in order to set a regulatory framework to guide public and private extension throughout the country (DOA, 2014). The policy states that extension and advisory services should be relevant, efficient, accountable and sustainable, and that extension should support sustainable agriculture. 
The policy notes that South African extension faces "major challenges in the areas of relevance, efficiency, accountability and sustainability" and that it needs to be sufficiently flexible to "respond to a wide set of local, national and global pressures to the agriculture, forestry and fishery sectors across [many] value chains" (DOA, 2014:4). The policy does not specifically provide details on the sustainability of extension, however, it does provide some clues. The policy suggests that extension is sustainable when:

- Extension operates within a "developmental and systems approach" in which extension workers "have a holistic view and understand the total value chain and linkages";

- Extension is governed and operates within a common set of principles and values;

- Extension genuinely responds to the needs, aspirations, opportunities and other circumstances of the many actors in the respective value chains;

- Extension workers trained with a multidisciplinary approach capacitating them with relevant and diverse knowledge and tools while retaining subject-specific technical knowledge and skills;

- Extension reaches beyond just production aspects of farming and addresses other elements of the value chain and subsectors such as forestry and fisheries - and these in the context of sustainable economic development;

- A holistic and collaborative approach is applied in a truly decentralised and pluralistic approach in which all role-players, stakeholders and service providers work together and share knowledge and information; and

- The extension service is directly accountable to clients at field level (DOA, 2014: 4-6).

Figure 1 portrays the proposed arrangement for coordinating and delivering extension in South Africa. The National Department of Agriculture, Forestry and Fisheries (DAFF) will establish a National Extension Forum whose members are drawn from public, private and NGO-sector stakeholders and role-players within the agri-food system. Each of South Africa's nine provinces (these include Gauteng (GP), Free State (FS), Mpumalanga (MP), Limpopo (L), Eastern Cape (EC), Western Cape (WC), Northern Cape (NC), North West (NW), and KwaZulu Natal $(\mathrm{KZN})$ ) will have a provincial extension coordinating forum as well as district extension forums through the province (DOA, 2014). The forums will articulate, prioritise and coordinate the provision of extension and advisory services within their respective designated geographical areas.

Similar to the National Forum, provincial and district forums will comprise of relevant stakeholders from the public, private and NGO sectors, including farmers and others in the value chain. The composition of the forum is determined by the policy and may be extended or reduced depending on the scope of the forum. Information relevant to coordinating extension should flow in all directions within the system - not merely top-down. This underscores the intended collaborative mode of this proposed approach to coordinating extension. It is also in keeping with operating holistically and collaboratively using a systems approach and makes extension more accountable at the 'field level' - all of which are needed to ensure the sustainability of extension. Although not expressively articulated in the policy, this proposed arrangement for coordination will also encourage and facilitate learning. 


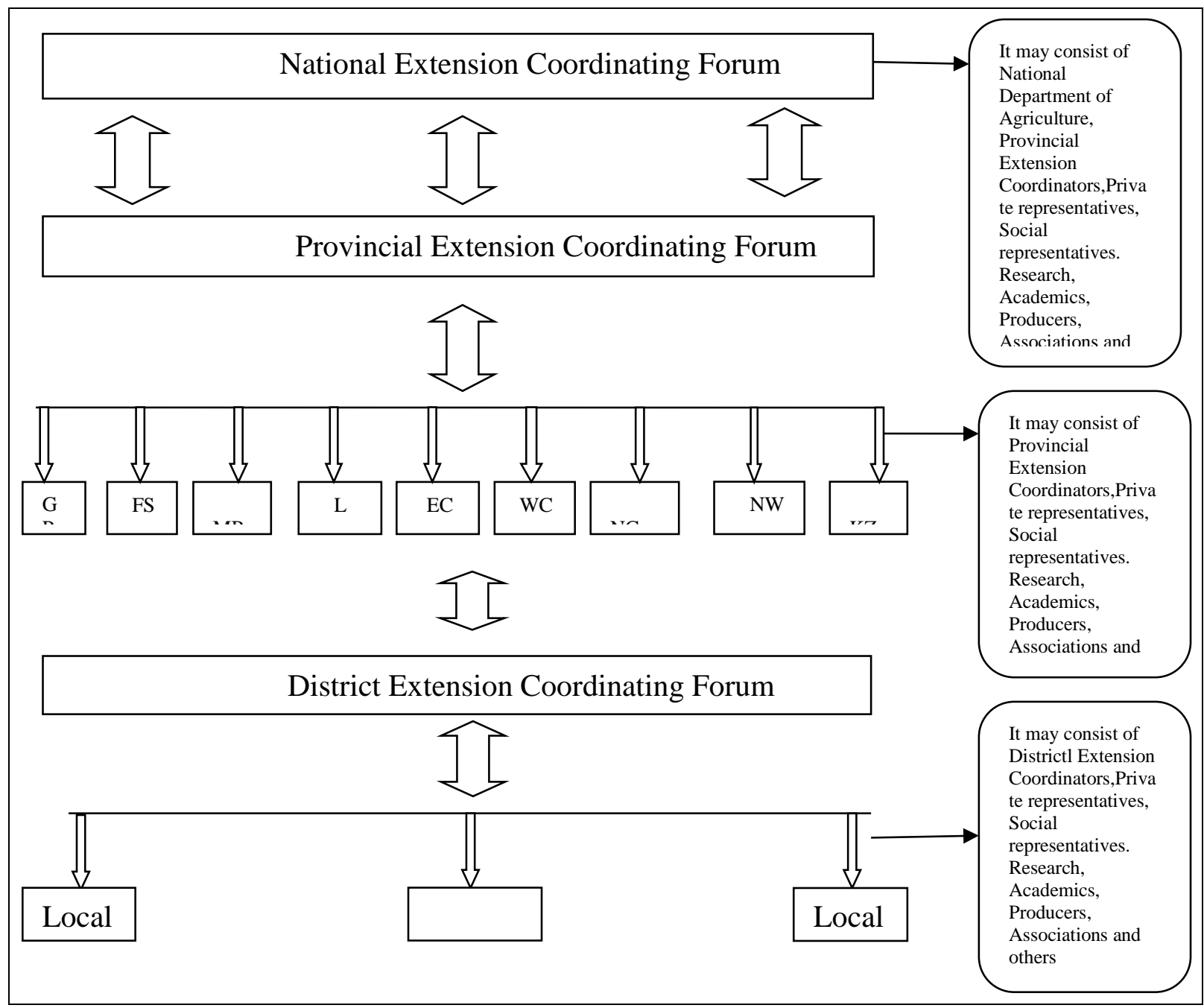

Figure 1: Institutionalisation of extension coordination forum in South Africa Adapted from Draft National Policy on Extension and Advisory services (DOA, 2014).

\subsection{Extension Recovery Plan}

The Extension Recovery Plan (ERP) was developed to capacitate or revitalise extension and advisory services in the country. This initiative sought to address various challenges and limitations in the sustainability of farmers and farming activities. The five strategic objectives or pillars of the ERP initiative are to: ensure visibility and accountability of extension; promote professionalism and improve the image of extension; recruit extension personnel; re-skill and re-orientate extension workers; provide information and communication technology (ICT) and other resources (DOA, 2011).

\subsection{Norms and Standards for Agricultural Extension (NSAEAS)}

Norms and Standards for South African Extension and Advisory Services were also developed as a result of a lack of framework for these services (DOA, 2005). Among other objectives, the Norms and Standards promote participatory approaches to extension and advisory services that lead to sustainable income generation by extension's clients in the context of fostering learning 
on sustainable agricultural production, including the conservation of natural resources. The Norms and Standards specifically define sustainability with seven factors, namely productivity, risk reduction, protection of the environment, economic viability, social acceptability, technical feasibility, and commercial feasibility (DOA, 2005).

In addition, the Norms and Standards emphasise strengthening the link between research, extension and farmers to promote research that supports sustainable agriculture. Finally, the Norms and Standards also emphasise the need to revitalise curriculum at institutions of higher education. The curriculum should enable extension practitioners to address issues such as increasing food security, economic growth, globalisation and environmental conservation (DOA, 2005).

\subsection{National Development Plan}

The National Development Plan (NDP) is considered a major step in the process of charting a new path for the Republic of South Africa - including promoting agriculture as an important path to eliminate poverty, reduce inequalities and redress the imbalances caused by apartheid. It is anticipated that much agricultural land will be urbanised which potentially creates uncertainties regarding food production and food insecurity. The NDP encourages moving away from unsustainable use of natural resources, expressing the need to reduce carbon emissions, and the concern that water for agriculture and drinking is becoming scarce and exhorting farmers to use water-conserving irrigation methods.

The NDP also addresses social protection in terms of improving livelihoods, pronouncing that eliminating poverty and reducing inequalities are the main drivers of social solidarity. The NDP emphasises that South Africa's agricultural potential is much larger than its current output; that the low potential is as a result of poor access to agricultural land and environmental degradation of land controlled by foreign and private entities. The NDP proposes a 'green revolution' to encourage food security by promoting sustainable agriculture among smallholder farmers.

\section{FINDINGS AND IMPLICATIONS OF THE STUDY}

The main objective of this study was to evaluate South African public agricultural extension and its alignment to the five pillars of sustainable agriculture. The premise of the study was that there is no inclusive policy dealing specifically with sustainable agricultural practices in South Africa (Khwidzhili \& Worth, 2017). Thus, it was necessary to study various policies to determine the criteria being used when discussing or promoting sustainable agriculture. To facilitate this discussion, each of the five pillars is discussed.

\subsection{Maintaining and increasing biological productivity}

The NPEAS refers several times to improving productivity of agricultural production, with an emphasis on the production of food. However, no reference is made to organic matter in the soil, which is a key factor in sustained productivity. The ERP developed to capacitate extension and advisory services, focuses on improving the role of extension and advisory services with reference to promoting sustainable agricultural practices. However, no reference is made to biological productivity. The NSAEAS provides a framework for conducting extension, with specific reference to "improved agricultural productivity" (DOA, 2011:2) and includes it as part of sustainability (DOA, 2011:4), but with little elucidation about it except that it is a 
function of innovation. The NDP emphasises the production of food to eliminate food insecurity by 2030 .

\subsection{Decreasing the level of risk to ensure larger security}

This pillar is often confused with economic viability. While they are related, they are separate elements of sustainability. The NPEAS and the ERP both conflate risk and economic viability into the traditional economic viability pillar of sustainability, thus, losing the nuance of risk which is inherent in agricultural production and therefore cannot be totally eliminated. The ERP refers to risk in relation to agriculture, noting only that extension should (among other things) address "dealing with changing patterns of risk" and that risk reduction is part of sustainable production (DOA, 2011:1). The NDP broadly discusses risk across all development endeavours covered by the policy, and in particular, lifestyle risks faced by individuals. Specifically, it refers to climate-change risk and the related risk of insufficient irrigation water. It raises concern regarding bio-security risk in the context of promoting export-quality production from smallholder farmers, however, it does not specifically speak to risk in agricultural development as an element of sustainability.

\subsection{Protecting the quality of natural resources}

This pillar is well-emphasised in all four policies. This is not unexpected as it originates from the three traditional pillars of sustainable agriculture. It is, however, always referred to as environmental viability. It is noted that the policies, not dissimilar to literature on sustainable agriculture, integrate this pillar with biological productivity - masking the distinct role of biological productivity in sustainable agriculture. This is the case with the NPESA and the ERP which define this pillar in terms of environmental viability. The NSAEAS specifically refers to the objectives of "endowing farmers with skills and knowledge for ensuring sustainable resource management" (DOA, 2005:2) and cites this as a specific function of extension.

The NDP refers specifically to the need to address the "extreme pressure on natural resources", which resources it states, "include its adjacent oceans, soil, water, biodiversity, sunshine and a long coastline" (NDP, 2013:47). To achieve this, the intention is to establish an environmental framework that indicates which natural resources need to be publicly monitored. As noted, the NDP makes specific reference to "long-term planning to promote biodiversity and the conservation and rehabilitation of natural assets" (NDP, 2013:201). Specifically needing attention is "damage to the environment includes soil loss due to erosion, loss of soil fertility, salination and other forms of degradation" and the harmful practices where "water extraction for irrigation is exceeding rates of replenishment" (NDP, 2013:92).

\subsection{Ensuring agricultural production is economically viable}

This is one of the three traditional pillars of sustainable agriculture. Thus, it would be reasonable to expect to find reference to it in each of the policies reviewed. However, this is not the case. The NPEAS refers to economic viability in the context that extension should foster "economic sustainability of the agriculture, forestry and fishery sectors" (DOA, 2014:4), and with specific reference to land reform. The NSAEAS indicates that extension "projects/ activities must consider economic impacts" and includes "economic viability" (together with 
"commercial feasibility") as a part of its definition of sustainability (DOA, 2014:4). The ERP makes no mention of economically viable agricultural production. The NDP alludes to the need for land reform to result in economically viable agricultural production; otherwise it makes no reference to the economic viability of agriculture.

\subsection{Ensuring agricultural production is socially acceptable}

Like economic viability, social acceptability is also one of the original pillars of sustainability and it should appear in each of the policies reviewed. Surprisingly, there is little reference to social acceptability in agriculture. The NPEAS notes that extension should lead to "wise decision-making about the socially...sustainable use of resources" in farmers' efforts to advance their livelihoods. It also notes that, in the pursuit of commercialisation, more attention must be given to social impacts of commercialisation. The NSAEAS indicates that extension "projects/ activities must... consider... social...impacts" and includes "social acceptability" as a part of its definition of sustainability (DOA, 2014:4). The ERP makes no reference to social acceptability in any context. The NDP considers social acceptability as fundamental to sustainable development. It refers to the need to produce food that is socially acceptable.

\section{CONCLUSION}

This paper provided a succinct evolution of agricultural extension in South Africa with special emphasis that extension services were imposed on farmers through the transfer of technology extension approaches. Since its inceptions in South Africa, agricultural extension is now recognised by the South African Council for Natural Science Profession (SACNASP). This implies that agricultural extension practitioners should register as scientists. The implication for this is that extension should work under a code of conduct regulated by SACNASP. Drawing from the evidence presented in this paper, it can be argued that South African public agricultural extension is best placed to promote sustainable agriculture through the five pillars of sustainability. Apart from the conventional approaches, there are a number of models that the extension could use to disseminate information. The definition of agricultural extension was highlighted starting from the early years, beginning of the second millennium and beyond. The paper highlighted the role of public extension services in South Africa.

The promotions of sustainable agricultural practices amongst farmers remains the domain of public extension in South Africa. Central to promotion of sustainable agricultural practices is the knowledge, skills and insight concerning the multifaceted process of changing farmers' behaviours. The national policy on extension and advisory services serves as a framework guiding the role of different stakeholders that are involved in public extension services. The extension and advisory policy supports the establishments of extension coordinating forums ranging from districts, provincial and national. These forums will be vital in promoting sustainable agricultural practices provided that all stakeholders remain relevant. Judging from its composition, which ranges from researchers, academics, private sector, associations, social representatives and others, these forums could play a pivotal role in shaping the landscape of extension and advisory services in South Africa.

The paper also identified other initiatives by the government to support extension and advisory services. These initiatives include, amongst others, the extension recovery plan (ERP) and the norms and standards for extension and advisory services. The paper also confirmed that a four year degree in agriculture is required in order to practice extension and advisory services in South Africa. The study also observed that in a few years to come, no one will be allowed or 
appointed as an extension practitioner if they are not registered with SACNASP. Registration to SACNASP should be preceded by registering to the South African Society of Agricultural Extension. SASAE is the voluntary organisation which acts as a mouthpiece of advocating extension and advisory services in the country. Finally, the establishment of a national policy on sustainable agricultural practices would serve as a compliment for the national policy on extension and advisory services in South Africa.

\section{REFERENCES}

ABDU-RAHEEM, K.A. \& WORTH, S.H., 2011. Household food security in South Africa: Evaluating extension's paradigm relative to the current food security and development goals. S. Afr. J. Agric. Ext., 39(2):91-103.

AGRAWAL, A., 1995. Indigenous and scientific knowledge: Some critical comments. Indigenous Knowledge Monitor, 3(3):1-6.

AJEIGBE, H.A. \& DASHIELL, K., 2010. Participatory research extension approach: N2Africa extension method. Putting nitrogen fixation to work for smallholder farmers in Africa (N2Africa). International Institute of Tropical Agriculture (IITA).

ALEX, G., ZIJP, W. \& BYERELEE, D., 2001. Rural extension and advisory services - New directions. Rural development strategy background paper No. 9, Washington, D.C: Agriculture and Rural Development Department, World Bank.

ANAETO, F.C., ASIABAKA, C.C., NNADI, F.N., AJAERO, J.O., AJO, O.O., UGWOKE, F.O., UKPONGSON, M.U. \& ONWEAGBA, A.E., 2012. The role of extension officers and extension services in the development of agriculture in Nigeria. J. Agric. Res., 1(6):180-185.

ANDERSON, J.R. \& FEDER, G., 2007. Agricultural extension, in Evenson, R. \& Pingali, P (eds.). Handbook of Agricultural Economics, vol. 3, Elsevier, 2343-2378.

BELAY, K. \& ABEBAW, D., 2004. Challenges facing agricultural extension agents: A case study from South Western Ethiopia. Afr. Dev. Rev., 16(1):139-168.

BEMBRIDGE, T.J., 1979. Effective agricultural extension. SA Institute for Agricultural Extension Natal Branch SASAE.

BEMBRIDGE, T.J., 1991. The practice of agricultural extension: A training manual. Development Bank of Southern Africa.

BIRKHAEUSER, D., EVENSON, R.E. \& FEDER, G., 1991. The economic impact of agricultural extension: A review. Econ. Dev. Cult. Change, 39(3):607-640.

CHAMBERS, R., 1997. Whose reality counts? Putting the first last. London: Intermediate Technology.

COHEN, L., MANION, L. \& MORRISON, K., 2002. Research methods in education. Routledge. 
DE KLERK, M., DRIMIE, S., ALIBER, M., MINI, S., MOKOENA, R., RANDELA, R., MODISELLE, S., VOGEL, C., DE SWARDT, C. \& KIRSTEN, J., 2004. Food security in South Africa: key policy issues for the medium term. Human Sciences Research Council.

DEPARTMENT OF AGRICULTURE (DOA)., 2005. Norms and standards for extension and advisory services in agriculture. Directorate: Scientific Research Development. Pretoria: Republic of South Africa.

DEPARTMENT OF AGRICULTURE (DOA)., 2011. Annual Report. Performance of the Extension Recovery Plan. National Department of Agriculture, Forestry and Fisheries; Pretoria: Republic of South Africa.

DEPARTMENT OF AGRICULTURE (DOA), 2014. National policy on extension and advisory services. National Department of Agriculture, Forestry and Fisheries. Pretoria: Republic of South Africa.

DEXTER, E., 1986. Strategies in the transfer of agricultural technology, with reference to Northern Europe, in Jones G.E. (ed.), Investing in rural extension: Strategies and goals, London: Elsevier Applied Science Publishers, 121-127.

DÜVEL, G.H., 2004. Developing an appropriate extension approach for South Africa: Process and outcome. S. Afr. J. Agric. Ext., 33(1):1-10.

DÜVEL, G.H., 2005. Principles, realities and challenges regarding institutional linkages for participatory extension and rural development in South Africa. S. Afri. J. Agric. Ext., 34(2):188-200.

EXTENSION RECOVERY IMPLEMENTATION PLAN., 2008. Presentation done during Department of Agriculture workshops and meetings in 2007-2008.

GRIFFITH, W.S., 1994. Applying learning theory in extension work, in Blackburn, D.J. (ed.), Extension handbook: Processes and practices. Toronto: Thompson Educational Publishing.

HAGMANN, J., CHUMA, E., MURWIRA, K. \& CONNOLLY, M., 1999. Putting process into practice: Operationalising participatory extension. Odi Agricultural Research \& Extension Network, Network Paper No. 94.

HART, T.G.B., 2003. Land reform: What have we learned? S. Afri. J. Agric. Ext., 33(1):15-27.

HEDDEN-DUNKHORST, B. \& MOLLEL, N.M., 1999. Small-scale farming and extension in South Africa's Northern Province S. Afr. J. Agric. Ext., 28:93-107.

KAIMOWITZ, D., 1991. The Evolution of Links between Extension and Research in Developing Countries, in Rivera, W.M. \& Gustafson, D.J. (eds.), Agricultural Extension: Worldwide Institutional Evolution and Forces for Change, Amsterdam: Elsevier Science, 101-12. 
KOCH, B.H. \& TERBLANCHE, S.E., 2013. An overview of agricultural extension in South Africa. S. Afr. J. Agric. Ext., 41(1):107-117.

KOLB, D.A., 1984. Experiential learning: Experiences as source of learning and development. Eglewood Cliffs, NJ: Prentice Hall.

KHWIDZHILI, R.H. \& WORTH, S.H., 2016. The sustainable agriculture imperative: Implications for South African agricultural extension. S. Afr. J. Agric. Ext., 44(2):19-29.

KHWIDZHILI, R.H. \& WORTH, S.H., 2017. Evaluation of policies promoting sustainable agriculture in South Africa. S. Afr. J. Agric. Ext., 45(2):73-85.

LEEUWIS, C. \& VAN DEN BAN, A., 1996. Communication for rural innovation: Rethinking agricultural extension. Oxford, UK: Blackwell Science

MAGORO, M.D. \& HLUNGWANI, S.S., 2014. The role of agricultural extension in the 21st century: Reflections from Africa. Int. J. Agric. Ext., 2(1):89-93.

MASERE, T.P. \& WORTH, S., 2016. Applicability of APSIM in decision-making by smallscale resource-constrained farmers: A case of lower Gweru communal area, Zimbabwe. JIAEE, 22(3):20-34.

NAGEL, U.J., 1997. Alternative Approaches to Organizing Extension, in Swanson, B., Bentz, R.P., \& Sofranko, A.J. (eds.), Improving Agricultural Extension: A Reference Manual, Roma: FAO.

NATIONAL DEVELOPMENT PLAN., 2013. Our future - make it work: National Development Plan 2030. National Planning Commission

NDORO, J.T., MUDHARA, M. \& CHIMONYO, M., 2014. Livestock extension programmes participation and impact on smallholder cattle productivity in KwaZulu-Natal: A propensity score matching approach. S. Afr. J. Agric Ext., 42(2):62-80.

NGOMANE, T., THOMSON, J.S. \& RADHAKRISHNA, R.B., 2002. Public sector for the agricultural extension systems in the Northern Province of South Africa. JIAEE., 9(3):3237.

NEL, E. \& DAVIES, J., 1999. Farming against the odds: An examination of the challenges facing farming and rural development in the Eastern Cape Province of South Africa. Appl. Geogr., 19(3):253-274.

NEUCHATEL GROUP, 2002. Common framework on financing agricultural and rural extension, Lindau: Swiss Centre for Agricultural Extension and Rural Development.

OLADELE, O.I. \& MABE, L.K., 2010. Job burnout and coping strategies among extension officers in North West province, South Africa. Afr. J. Agric. Res., 5(17):2321-2325.

PURCELL, D.L. \& ANDERSON, J.R., 1997. Agricultural extension and research: Achievements and problems in national systems. The World Bank. 
RIVERA, W.M., 2006. Agricultural knowledge and development in a new age and a different world. JIAEE, 13(2):57-67.

RIVERA, W.M., QAMAR, M.K. \& CROWDER, L.V., 2001. Agricultural and rural extension worldwide: Options for institutional reform in the developing countries. Rome: FAO.

RÖLING, N., 1995. Extension science. Cambridge: Cambridge University Press.

SWANSON, B.E., 2006. The changing role of agricultural extension in a global economy. JIAEE, 13(3):5-17.

VAN DEN BAN, A.W. \& HAWKINS, H.S., 1996. Agricultural extension. Oxford: Blackwell Science.

VAN NIEKERK, J.A., STROEBEL, A., VAN ROOYEN, C.J., WHITFIELD, K.P. \& SWANEPOEL, F.C.J., 2011. Towards redesigning a new agricultural extension services in South Africa: Views and proposals of extensionists in the Eastern Cape. S. Afr. J. Agric. Ext., 38:57-68.

VAN VUUREN, J.P.J., 1952. Agricultural extension services. Farming in South Africa, 27(312):227-230.

WETTASINHA, C., VELDHUIZEN VAN, L. \& WATERS-BAYER, A., 2003. Advancing participatory technology development: Case studies on integration into agricultural research, extension and education. Philippines: IIRR.

WILliAMS, B., MAYSON, D., DE SATGÉ, R., EPSTEIN, S. \& SEMWAYO, T., 2008. Extension and smallholder agriculture: Key issues from a review of the literature. Cape Town: Phuhlisani.

WORTH, S.H., 2006. Agriflection: A learning model for agricultural extension in South Africa. The Journal of Agricultural Education and Extension, 12(3):179-193.

WORTH, S., 2012. Agricultural extension in South Africa: Status Quo Report. Cape Town: Phuhlisani Solutions.

YIN, R.K., 2003. Case study research design and methods. California: SAGE Publications. 